\title{
Manganese-Induced Parkinsonism due to Ephedrone Abuse
}

\author{
Katrin Sikk, ${ }^{1}$ Sulev Haldre, ${ }^{1}$ Sten-Magnus Aquilonius, ${ }^{2}$ and Pille Taba ${ }^{1}$ \\ ${ }^{1}$ Department of Neurology and Neurosurgery, University of Tartu, L. Puusepa 8, 51014 Tartu, Estonia \\ ${ }^{2}$ Department of Neuroscience, Neurology, Uppsala University Hospital, 75185 Uppsala, Sweden
}

Correspondence should be addressed to Pille Taba, pille.taba@kliinikum.ee

Received 19 September 2010; Accepted 9 January 2011

Academic Editor: Neeraj Kumar

Copyright () 2011 Katrin Sikk et al. This is an open access article distributed under the Creative Commons Attribution License, which permits unrestricted use, distribution, and reproduction in any medium, provided the original work is properly cited.

\begin{abstract}
During recent years, a syndrome of hypokinesia, dysarthria, dystonia, and postural impairment, related to intravenous use of a "designer" psychostimulant derived from pseudoephedrine using potassium permanganate as the oxidant, has been observed in drug addicts in several countries in Eastern Europe with some cases also in Western countries. A levodopa unresponsive Parkinsonian syndrome occurs within a few months of abusing the homemade drug mixture containing ephedrone (methcathinone) and manganese. The development of this neurological syndrome has been attributed to toxic effects of manganese, but the role of the psychostimulant ephedrone is unclear. This paper describes the clinical syndrome, results of neuroimaging, and therapeutic attempts.
\end{abstract}

\section{Introduction}

Manganese (Mn) is an essential trace metal, present in most tissues. Excessive exposure to Mn may cause the development of a Parkinsonian syndrome known as manganism. The symptoms of chronic Mn intoxication were first reported by Couper in workers inhaling "black oxide of manganese" in an ore-grinding plant [1]. He described a difficulty of movement as paraplegia, accompanied by lack of facial expression, drooling, and impaired speech.

$\mathrm{Mn}$ is widely used in industry and is found in commercial products and industrial settings. Occupational inhalational exposure, especially in mining [2], smelting [3], and welding [4], has been the main cause of human Mn intoxication. Mn is used in the manufacture of steel and batteries, bactericidal agents, gasoline, and the water purification process. Manganism has also been described in nonoccupational settings, like long-term total parenteral nutrition [5], chronic liver failure [6], or exposure to contaminated well water [7].

Parkinsonism is a characteristic clinical manifestation of manganism, typically with symmetric bradykinesia, rigidity, gait disorder and falls, speech disturbance and sometimes with the presence of postural or action tremor. Dystonias in the face and limbs may develop; behavioural and cognitive changes have been described in the early course [8]. Blood manganese concentration reflects current exposure, and magnetic resonance imaging (MRI) typically shows accumulation of $\mathrm{Mn}$ in the brain, causing hyperintensity in T1-weighted sequences, mainly in the basal ganglia $[9,10]$. Parkinsonism caused by Mn exposure does not respond to levodopa treatment, but chelating therapy with calcium salt of ethylene diamine tetraacetic acid (CaNa2EDTA) may be of clinical benefit [11].

During the recent years, a levodopa unresponsive Parkinsonian syndrome associated with early falls, severe dysarthria, and prominent limb dystonia, has been described in individuals who have chronically administered a "designer" psychostimulant ephedrone (methcathinone) intravenously. The syndrome closely resembles a chronic manganic encephalopathy seen in manganese ore miners. Ephedrone, the oxidation product of ephedrine or pseudoephedrine, is a psychostimulant that has become a substantial drug of abuse in several countries [12]. The first cases of "ephedrone encephalopathy" were described in the Russian literature 20 years ago but this topic has gained growing international interest as several case series from Eastern Europe [13-17] and also some immigrant cases from Western Europe and Canada have been reported $[18,19]$.

It is difficult to estimate the scope of ephedrone abuse and the prevalence of $\mathrm{Mn}$-induced parkinsonism among abusers. According to a survey performed by the National Institute for Health Development in Estonia with 
a population of 1.34 million, there were approximately 13800 intravenous drug users in Estonia, among them 10000 living in Tallinn and its neighbouring areas, and 2500 in the north-eastern part of Estonia [20]. In a survey on risk behaviour in these areas, 700 intravenous drug users in Tallinn and Eastern Estonia were interviewed: $11 \%$ of the participants reported ephedrone use in their history, and $1.3 \%$ were current users [21].

The development of the neurological syndrome in ephedrone addicts has been largely attributed to the toxic effects of Mn. This is supported by the clinical signs that are consistent with the occupational manganism, and by the fact that Parkinsonian syndrome did not develop when ephedrone users had prepared the drug using potassium or sodium dichromate as the oxidation agent instead of potassium permanganate. This different chemical preparation has been observed in US clandestine laboratories, followed by several cleanup steps; the powder has been inhaled or sniffed, and an acute toxicity has been described as similar to amphetamine-like drugs but no neurologic sequelae have been reported [22].

The role of the psychostimulant ephedrone in developing Parkinsonism is unclear, as are the pathophysiological and pathoanatomical mechanisms of damage caused by the mixture. It is, however, possible that ephedrone itself may have pathogenic effects on nigral neurons compounding the risk; it affects the dopaminergic transporter in a manner resembling that of methamphetamine and causes increased dopamine release. Despite the absence of clinical signs of parkinsonism, dopaminergic dysfunction has been shown in abusers of the psychostimulants ephedrone (methcathinone) and methamphetamine, which are chemically related as methamphetamine is a reduction product of ephedrine or pseudoephedrine: $\left[{ }^{11} \mathrm{C}\right] \mathrm{WIN}-35,428$-PET study demonstrated a significant reduction in DAT density in caudate nucleus and putamen [23]. These findings have raised concerns that these psychostimulants may increase the risk of development of Parkinson's disease.

Historically, intravenous use of 1-methyl-4-phenyl1,2,5,6-tetrahydropyridine (MPTP), also known as a "synthetic heroin", has caused a severe Parkinsonian syndrome with rigidity, hypokinesia, gait disorder, and hallucinations within some weeks after starting injections of the drug. In $\left[{ }^{18} \mathrm{~F}\right]$ fluorodopa PET, there was a reduction of dopaminergic function in the caudate and putamen in MPTP users and levodopa therapy was effective $[24,25]$. Discovering of the ability of MPTP to produce selective nigral cell degeneration and parkinsonism in humans has been probably the greatest advance in experimental models of parkinsonism [26].

In the animal experiments, ephedrone had a strong stimulating effect in mice but during chronic administration of the drug, neither parkinsonism nor dystonias developed [27]. In a dose response study, the lethal outcome was caused by the lower doses of ephedrone as part of the mixture compared to pure ephedrone, which indicates the possible role of a neurotoxic potentiation by the components in the mixture [28].

To evaluate neurotoxicity of $\mathrm{Mn}$ and psychostimulants, experiments on nonhuman primates have been used including neuroimaging, neurochemical and neuropathological investigations. Nonhuman primates exposed to several sequential doses of psychostimulant 3,4-methylendioxymethamphetamine (MDMA, "Ecstasy"), developed severe brain dopaminergic neurotoxicity, additionally to less pronounced serotonergic neurotoxicity-it suggests that humans using MDMA are at high risk for brain dopaminergic injury [29]. In a nonhuman primate study, chronic Mn exposure resulted in a subtle motor function deficit but a marked decrease of dopamine release in the absence of terminal loss [30]. A longitudinal PET study in Mn-exposed nonhuman primates that included the administration of amphetamine indicated that motor function abnormalities are likely mediated by inhibition of dopamine release in the striatum [31].

The extrapyramidal syndrome in abusers of ephedrone has been referred to be caused by toxicity of high $\mathrm{Mn}$ load but despite the lack of evidence to link ephedrone with an increased risk for parkinsonism, it may have a potential to increase the risk of damage from manganese exposure.

\section{Synthesis and Chemical Analysis of Ephedrone}

Ephedrone is a psychostimulant drug that increases the release of catecholamines in the brain and has similar behavioural effects to methamphetamine. It is a synthetic $\mathrm{N}$-methyl analogue of cathinone which is found in the leaves of the khat bush (Catha edulis). Ephedrone causes acute effects including euphoria, agitation, anxiety, and hallucinations, similarly to methamphetamine and other amphetamines $[12,22]$.

Ephedrone mixture for injection is synthesised by the drug addicts from over-the-counter cold remedies containing ephedrine or pseudoephedrine (Sudafed). Potassium permanganate and acetic acid are added for inducing the oxidation. The solution made with boiling water is cooled, filtered through a cotton pad, and injected intravenously. Only $44 \%$ of pseudoephedrine was converted to ephedrone in the reaction. The concentration of $\mathrm{Mn}$ in the final synthetic mixture was found to be very high $-0.6 \mathrm{~g} / \mathrm{L}$ [14].

When injected dozens of times per day with a daily injection volume of $100-300 \mathrm{~mL}$, the daily load of $\mathrm{Mn}$ is 60-180 mg, an enormous overload compared to the recommended dose of $0.1 \mathrm{mg}$ of $\mathrm{Mn}$ as a maximum intravenous daily supplementation [32]. The estimated ephedrone content in the mixture is $4.4 \mathrm{mg} / \mathrm{mL}$, and thus the daily load is $400-1200 \mathrm{mg}$ of ephedrone. Instructions on how to produce this neurotoxic mixture are readily available on the Internet in several languages, and are widely spread among drug addicts. The ephedrone mixture has also been referred to as "Russian Cocktail", and by its street names "cat", "mulka", "murtsovka", and "Jeff". Making the drug is simple, all necessary components can be bought from the pharmacy without a prescription, and the instructions for preparation are readily available on the Internet. 


\section{Symptoms}

The first neurological symptoms-usually gait disturbance and slurred speech-have occurred only some months after the beginning of ephedrone injections [15] or up to 17 years later [17], but generally within the first few years. There is no correlation between the duration of drug abuse and clinical severity, and in some abusers, the syndrome does not develop at all, despite ephedrone use. The most characteristic reported neurological findings were postural instability with retropulsion and falls, gait disturbance, hypomimia, limb and face dystonia, dysarthria, hypophonia, and symmetric bradykinesia. Less frequently described symptoms were limb and axial rigidity, gait freezing, postural and resting tremor, micrographia, apraxia of eyelid opening, some slowing of vertical saccades, pathological laughter, palilalia, and primitive reflexes (Table 1). Though hyperactive deep tendon reflexes were common findings, pathological reflexes were mentioned only in one case [18]. Few cases had oromandibular dyskinesia, blepharospasm [37], myoclonus [33], or restriction of vertical saccadic eye movements [19].

Most authors have used the Unified Parkinson's Disease Rating Scale (UPDRS) for scoring motor function though it does not reflect the disability in details because some prominent symptoms are different from Parkinson's disease. Compared to Parkinson's disease, the disability in the ephedrone abusers is mainly caused by postural and gait impairment and dystonias in a relatively early phase of the disease. In UPDRS, only a few items in the motor score are related to gait and postural impairment, and there are more items for evaluation of tremor that is not characteristic sign for parkinsonism in ephedrone users. Combining UPDRS with Hoehn and Yahr staging, Schwab and England rating scale, and Parkinson's Disease Quality of Life Questionnaire gives better assessment of the syndrome severity.

The scores of the Mini Mental State Examination were normal. More extensive neuropsychological testing showed mild executive cognitive impairment including bradyphrenia, attenuated attention, reduced working capacity, decreased phonetic verbal fluency, and tendency to impulsiveness $[16,18,33,36]$.

After drug abuse discontinuation, usually there was no change, or there was even further progression of the motor impairment, but a few patients had slight improvement of their symptoms.

\section{Manganese Concentration}

Chronic exposure causes accumulation of $\mathrm{Mn}$ in blood and tissues. Active ephedrone users had increased levels of blood Mn (average $831 \mathrm{nmol} / \mathrm{L}$, range 201-2102) but former users had normal or slightly elevated blood $\mathrm{Mn}$ values (average $346 \mathrm{nmol} / \mathrm{L}$, range 114-727) [17]. Elevated Mn blood concentration was a characteristic feature that indicated continuing abuse of ephedrone; there was a significant difference when compared to the former drug users.

Manganese is eliminated rapidly from the blood, and thus blood levels of $\mathrm{Mn}$ may poorly reflect tissue Mn content.
In a Ukrainian study, scalp hair level showed overlap between controls and ephedrine-exposed cases but pubic hair $\mathrm{Mn}$ concentration was significantly elevated in patients with less than one year off ephedrone abuse $(1.94 \pm 1.60 \mu \mathrm{g} / \mathrm{g})$ compared with the controls $(0.34 \pm 1.60 \mu \mathrm{g} / \mathrm{g})$ [16].

\section{Neuroimaging}

Magnetic resonance imaging (MRI) of the brain in active ephedrone users showed symmetrical hyperintensity on T1-weighted images in the globus pallidus and substantia nigra pars reticulata (Figure 1). Less frequently involved structures were subthalamic nucleus, substantia innominata, putamen, caudate, anterior midbrain, pontine tegmentum, and dentate nucleus. In former users, the signal increase is less intense and not so widespread. MRI was already normal six months after the last exposure to ephedrone [37]. Some cases had increased signal intensity up to six years after cessation of drug abuse [17]. However, these cases had high concentration of $\mathrm{Mn}$ in blood, which could refer to other susceptibility factors like chronic liver disease or even to the continuous drug abuse.

Although MRI T1-weighted scans did not show abnormalities of white matter, diffusion tensor imaging has demonstrated widespread white matter abnormalities, particularly in central white matter and areas underlying the right ventral premotor cortex and medial prefrontal premotor cortex [38]. The detection of these abnormalities outside areas known to be connected directly to the globus pallidus suggests a more widespread neuronal pathology than previously demonstrated by conventional imaging techniques.

Single-photon emission computed tomography (SPECT) imaging with ${ }^{123}$ I Ioflupane (DaTSCAN) was performed in 10 former ephedrone addicts in three different centres and it showed a normal pattern of tracer uptake in all of the cases $[16,18,34]$.

6-Fluorodopa positron emission tomography (PET) in an active user revealed a mild reduction in presynaptic uptake limited to the posterior putamen [19]. This minor change could be adaptive to psychostimulant abuse. Fluorodeoxyglycose (FDG) PET in four former users showed a widespread but not uniform decrease of tracer uptake mainly in the basal ganglia and the surrounding white matter [34].

\section{Concomitant Infections}

The possible role of concomitant infections has been emphasised as parkinsonism may represent a manifestation of human immunodeficiency virus (HIV) encephalopathy. Clinically relevant movement disorders are not common in patients with HIV infection [39]; parkinsonism has been observed in $5 \%$ of HIV positive patients [40].

In the Latvian study with the highest number of the patients among the reports on ephedrone abuse, 20 of 23 patients (87\%) were positive for the HIV, and $45 \%$ of them had acquired immunodeficiency syndrome (AIDS). However, progressive Parkinsonian syndrome occurred also 


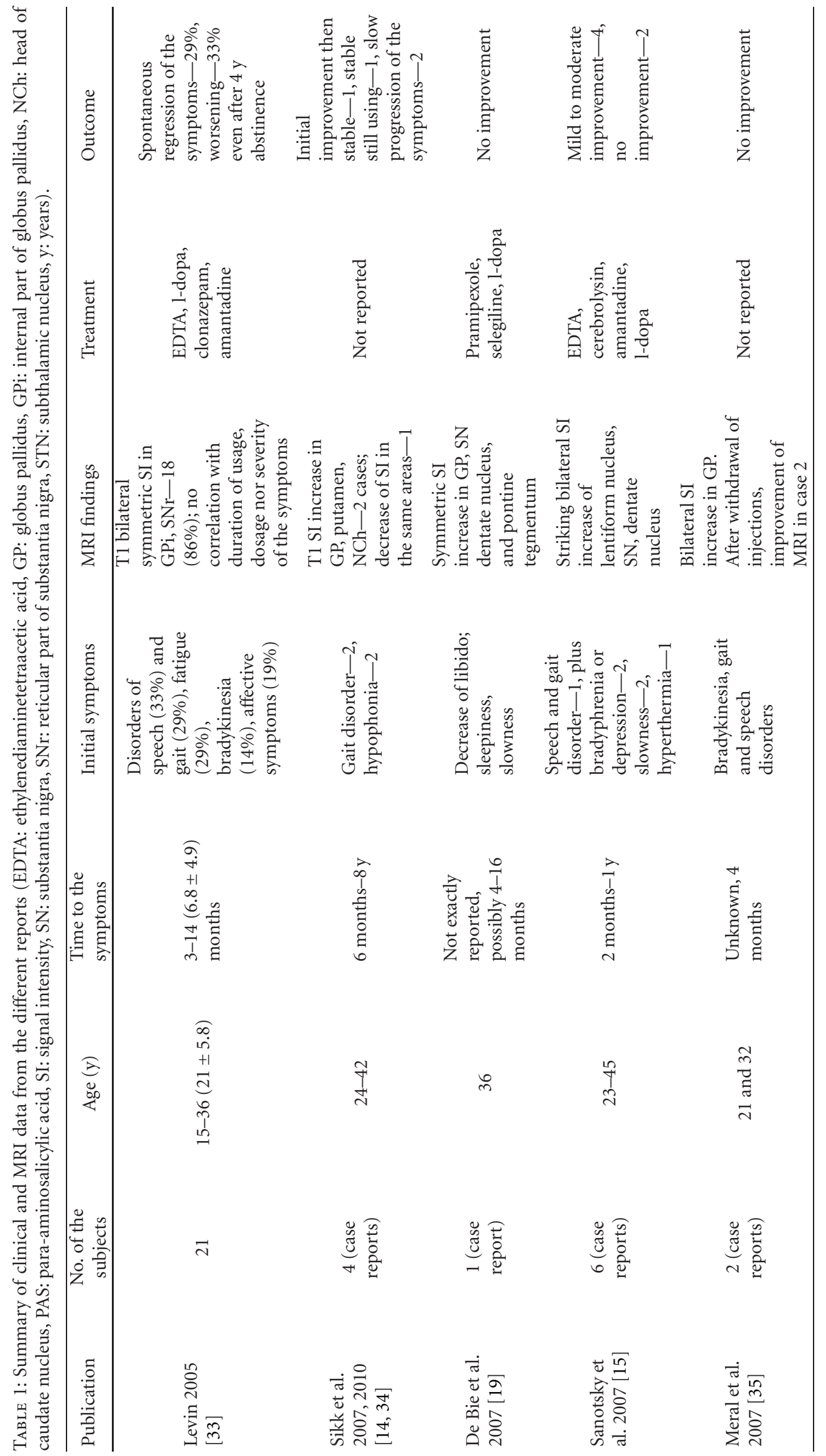




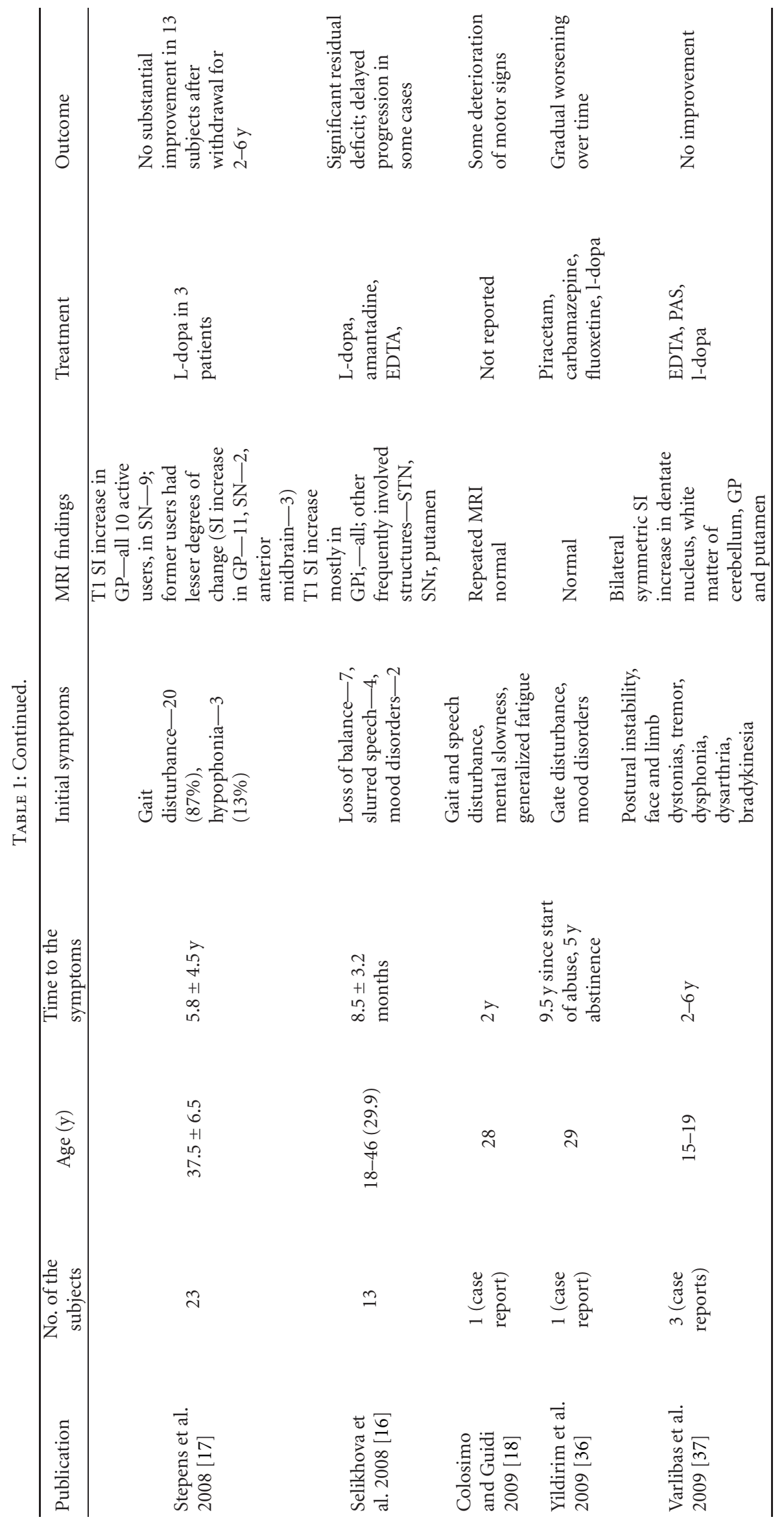




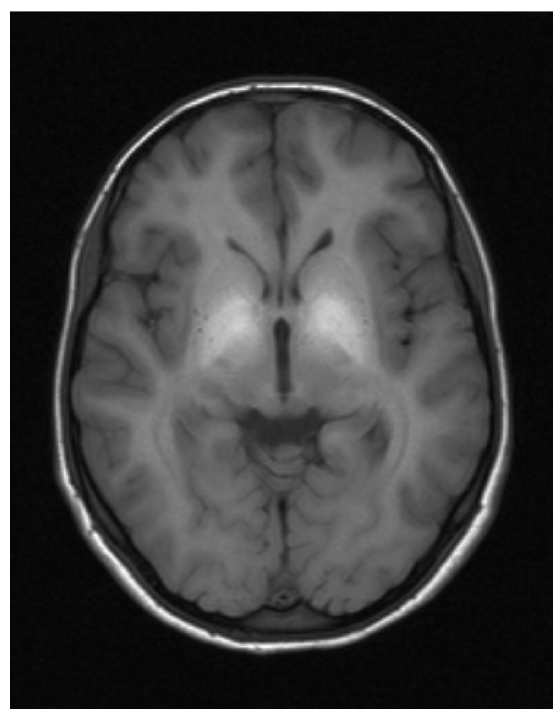

(a)

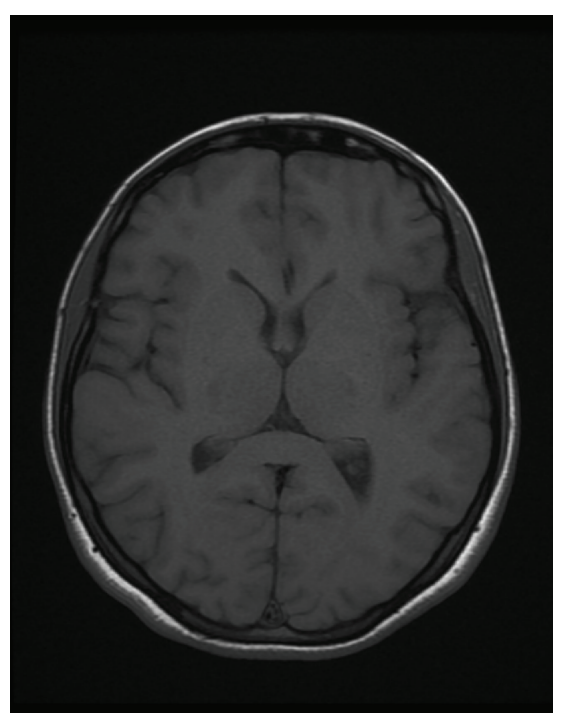

(b)

FIGURE 1: T1-weighted axial MRIs of the brain showing an increased signal in the globus pallidus in an active user and and two years after cessation of exposure.

in HIV-negative ephedrone users. Parkinsonian disorder in HIV encephalopathy is often related to HIV-associated dementia but the ephedrone users had normal cognitive function [17].

All the patients were positive for hepatitis $\mathrm{C}$ virus that is considered as a possible cause for extrapyramidal disease. Similar changes in the globus pallidus as described in ephedrone addicts, have been shown in patients with chronic hepatic disease and cirrhosis, but liver failure or cirrhosis have not been reported in any of the patients $[17,35]$. Thus, concomitant infectious diseases have no direct effect to the movement disorder that occurs as a consequence of illicit use of ephedrine, but they are related to the contamination during intravenous injection of drugs.

\section{Treatment}

The acute levodopa challenge tests were negative. Chronic levodopa therapy up to the maximum tolerated doses showed no improvement. Dopamine agonists were ineffective as well $[18,19]$. Some patients reported subjective shortterm improvement with amantadine [16]. There was no change [18], or there was a mild reduction [16] in dystonic symptoms with anticholinergic drugs.

Chelating treatment with ethylenediaminetetraacetic acid (EDTA) reduced blood Mn levels, but did not affect symptoms $[17,37]$, or led to a mild improvement probably related to abstinence $[15,16]$. Para-aminosalicylic acid (PAS), another medication with chelating properties, did not change clinical findings [37].

Generally, the syndrome is unresponsive to levodopa and other antiParkinsonian medication, and there is also no other effective treatment that could continuously improve
Parkinsonian or dystonic symptoms in the ephedrone users. Even when mild improvement observed, it has been in the short-term, and the condition may worsen progressively despite discontinuation of injecting the drug.

\section{Conclusions}

Mn-induced extrapyramidal system damage develops in ephedrone abusers due to the accumulation of $\mathrm{Mn}$ in the basal ganglia. Ephedrone could have additive neurotoxic effect to the progression of parkinsonism, but the existing evidence is inconclusive. Concomitant infections have no direct effect on the development of the syndrome. Manganese metabolism in blood is fast, tissue concentrations remain high much longer. Functional neuroimaging studies and lack of levodopa response confirm that the presynaptic neurons in the nigrostriatal pathway are intact. According to FDG PET study, changes in brain metabolism are more widespread mainly located in the central part of the brain including the basal ganglia, thalami, and the surrounding white matter.

Ephedrone addiction is an alarming new cause of toxic parkinsonism. Ephedrone is a widespread recreational drug because it is relatively cheap and easy to prepare. The described cases could be just "the tip of the iceberg". In the most extreme cases, only a few months of ephedrone abuse could lead to severe and progressing disability.

The prognosis of the Parkinsonian syndrome in ephedrone users is poor as there is no curative therapy. The addicts seem to be unaware of the long-term side effects and deterioration. Though presently reported mainly in Eastern Europe, a global spread might occur, and the diagnosis needs to be considered within the social risk groups anywhere. 


\section{References}

[1] J. Couper, "On the effects of black oxide of manganese when inhaled into the lungs," British Annals of Medicine and Pharmacology, vol. 1, pp. 41-42, 1837.

[2] P. Schuler, H. Oyanguren, V. Maturana et al., "Manganese poisoning; environmental and medical study at a Chilean mine," Industrial Medicine \& Surgery, vol. 26, no. 4, pp. 167173, 1957.

[3] J. D. Wang, C. C. Huang, Y. H. Hwang, J. R. Chiang, J. M. Lin, and J. S. Chen, "Manganese induced parkinsonism: an outbreak due to an unrepaired ventilation control system in a ferromanganese smelter," British Journal of Industrial Medicine, vol. 46, no. 12, pp. 856-859, 1989.

[4] K. A. Josephs, J. E. Ahlskog, K. J. Klos et al., "Neurologic manifestations in welders with pallidal MRI T1 hyperintensity," Neurology, vol. 64, no. 12, pp. 2033-2039, 2005.

[5] S. Nagatomo, F. Umehara, K. Hanada et al., "Manganese intoxication during total parenteral nutrition: report of two cases and review of the literature," Journal of the Neurological Sciences, vol. 162, no. 1, pp. 102-105, 1999.

[6] K. J. Klos, J. E. Ahlskog, K. A. Josephs, R. D. Fealey, C. T. Cowl, and N. Kumar, "Neurologic spectrum of chronic liver failure and basal ganglia $\mathrm{T} 1$ hyperintensity on magnetic resonance imaging: probable manganese neurotoxicity," Archives of Neurology, vol. 62, no. 9, pp. 1385-1390, 2005.

[7] A. B. Santamaria and S. I. Sulsky, "Risk assessment of an essential element: manganese," Journal of Toxicology and Environmental Health A, vol. 73, no. 2-3, pp. 128-155, 2010.

[8] D. P. Perl and C. W. Olanow, "The neuropathology of manganese-induced parkinsonism," Journal of Neuropathology and Experimental Neurology, vol. 66, no. 8, pp. 675-682, 2007.

[9] M. Aschner, K. M. Erikson, E. H. Hernández, and R. Tjalkens, "Manganese and its role in Parkinson's disease: from transport to neuropathology," Neuromolecular Medicine, vol. 11, no. 4, pp. 252-266, 2009.

[10] D. S. Choi, E. A. Kim, H. K. Cheong et al., "Evaluation of MR signal index for the assessment of occupational manganese exposure of welders by measurement of local proton $\mathrm{T}$ relaxation time," NeuroToxicology, vol. 28, no. 2, pp. 284-289, 2007.

[11] E. H. Hernandez, G. Discalzi, C. Valentini et al., "Follow-up of patients affected by manganese-induced Parkinsonism after treatment with CaNa2EDTA," NeuroToxicology, vol. 27, no. 3, pp. 333-339, 2006.

[12] K. Y. Zhingel, W. Dovensky, A. Crossman, and A. Allen, "Ephedrone: 2-methylamino-1-phenylpropan-1-one (Jeff)," Journal of Forensic Sciences, vol. 36, no. 3, pp. 915-920, 1991.

[13] T. Schmidt and D. Dalubaeva, "Neurological complications of ephedrone drug abuse (ephedrone encephalopathy)," in Anniversary Collection: Diagnostic and Treatment of Neurological Diseases, pp. 183-186, Medicine, Moscow, Russia, 1990.

[14] K. Sikk, P. Taba, S. Haldre et al., "Irreversible motor impairment in young addicts-ephedrone, manganism or both?" Acta Neurologica Scandinavica, vol. 115, no. 6, pp. 385-389, 2007.

[15] Y. Sanotsky, R. Lesyk, L. Fedoryshyn, I. Komnatska, Y. Matviyenko, and S. Fahn, "Manganic encephalopathy due to "ephedrone" abuse," Movement Disorders, vol. 22, no. 9, pp. 1337-1343, 2007.

[16] M. Selikhova, L. Fedoryshyn, Y. Matviyenko et al., "Parkinsonism and dystonia caused by the illicit use of ephedrone-a longitudinal study," Movement Disorders, vol. 23, no. 15, pp. 2224-2231, 2008.
[17] A. Stepens, I. Logina, V. Liguts et al., "A Parkinsonian syndrome in methcathinone users and the role of manganese," New England Journal of Medicine, vol. 358, no. 10, pp. 10091017, 2008.

[18] C. Colosimo and M. Guidi, "Parkinsonism due to ephedrone neurotoxicity: a case report," European Journal of Neurology, vol. 16, no. 6, pp. e114-e115, 2009.

[19] R. M. A. De Bie, R. M. Gladstone, A. P. Strafella, J. H. Ko, and A. E. Lang, "Manganese-induced parkinsonism associated with methcathinone (Ephedrone) abuse," Archives of Neurology, vol. 64, no. 6, pp. 886-889, 2007.

[20] A. Uusküla, K. Rajaleid, A. Talu, K. Abel, K. Rüütel, and G. Hay, "Estimating injection drug use prevalence using state wide administrative data sources: Estonia, 2004," Addiction Research and Theory, vol. 15, no. 4, pp. 411-424, 2007.

[21] L. Lõhmus, K. Rüütel, K. Abel-Ollo, H. M. Loit, A. Talu, and A. Uusküla, Prevalence of HIV and other infections, and risk behavior among injecting drug abusers in Tallinn and KohtlaJärve, National Institute for Health Development, Department of Public Health, University of Tartu, 2008.

[22] T. S. Emerson and J. E. Cisek, "Methcathinone: a Russian designer amphetamine infiltrates the rural midwest," Annals of Emergency Medicine, vol. 22, no. 12, pp. 1897-1903, 1993.

[23] U. D. McCann, D. F. Wong, F. Yokoi, V. Villemagne, R. F. Dannals, and G. A. Ricaurte, "Reduced striatal dopamine transporter density in abstinent methamphetamine and methcathinone users: wvidence from positron emission tomography studies with $\left[{ }^{11} \mathrm{C}\right] \mathrm{WIN}-35,428$," Journal of Neuroscience, vol. 18, no. 20, pp. 8417-8422, 1998.

[24] J. W. Langston, P. Ballard, J. W. Tetrud, and I. Irwin, "Chronic parkinsonism in humans due to a product of meperidineanalog synthesis," Science, vol. 219, no. 4587, pp. 979-980, 1983.

[25] B. J. Snow, F. J. G. Vingerhoets, J. W. Langston, J. W. Tetrud, V. Sossi, and D. B. Calne, "Pattern of dopaminergic loss in the striatum of humans with MPTP induced parkinsonism," Journal of Neurology Neurosurgery and Psychiatry, vol. 68, no. 3, pp. 313-316, 2000.

[26] P. Jenner, "Functional models of Parkinson's disease: a valuable tool in the development of novel therapies," Annals of Neurology, vol. 64, no. 2, pp. S16-S29, 2008.

[27] A. Asser, S. Kõks, M. Haaparanta-Solin et al., "The effects of chronic administration of ephedrone (methcathinone) and manganese in mice," Movement Disorders, vol. 24, supplement 1, pp. S48-S49, 2009.

[28] A. Asser, S. Kõks, U. Soomets et al., "Acute effects of methcathinone and manganese in mice: a dose response study," Movement Disorders, vol. 25, no. S2, p. S226, 2010.

[29] G. A. Ricaurte, J. Yuan, G. Hatzidimitriou, B. J. Cord, and U. D. McCann, "Severe dopaminergic neurotoxicity in primates after a common recreational dose regimen of MDMA ("Ecstasy")," Science, vol. 297, no. 5590, pp. 2260-2263, 2002.

[30] T. R. Guilarte, M. K. Chen, J. L. McGlothan et al., "Nigrostriatal dopamine system dysfunction and subtle motor deficits in manganese-exposed non-human primates," Experimental Neurology, vol. 202, no. 2, pp. 381-390, 2006.

[31] T. R. Guilarte, N. C. Burton, J. L. McGlothan et al., "Impairment of nigrostriatal dopamine neurotransmission by manganese is mediated by pre-synaptic mechanism(s): implications to manganese-induced parkinsonism," Journal of Neurochemistry, vol. 107, no. 5, pp. 1236-1247, 2008.

[32] D. B. Bertinet, M. Tinivella, F. A. Balzola et al., "Brain manganese deposition and blood levels in patients undergoing 
home parenteral nutrition," Journal of Parenteral and Enteral Nutrition, vol. 24, no. 4, pp. 223-227, 2000.

[33] O. S. Levin, “"Ephedron” encephalopathy," Zhurnal Nevrologii i Psihiatrii imeni S.S. Korsakova, vol. 105, no. 7, pp. 12-20, 2005.

[34] K. Sikk, P. Taba, S. Haldre et al., "Clinical, neuroimaging and neurophysiological features in addicts with manganeseephedrone exposure," Acta Neurologica Scandinavica, vol. 121, no. 4, pp. 237-243, 2010.

[35] H. Meral, Y. Kutukcu, B. Atmaca, F. Ozer, and K. Hamamcioglu, "Parkinsonism caused by chronic usage of intravenous potassium permanganate," Neurologist, vol. 13, no. 2, pp. $92-$ 94, 2007.

[36] E. A. Yildirim, A. Eşsizoğlu, A. Köksal, B. Doğu, S. Baybaş, and P. Gökalp, "Chronic manganese intoxication due to methcathinone (ephedron) abuse: a case report," Turkish Journal of Psychiatry, vol. 20, no. 3, pp. 294-298, 2009.

[37] F. Varlibas, I. Delipoyraz, G. Yuksel, G. Filiz, H. Tireli, and N. O. Gecim, "Neurotoxicity following chronic intravenous use of "Russian cocktail”"' Clinical Toxicology, vol. 47, no. 2, pp. 157-160, 2009.

[38] A. Stepens, C. J. Stagg, A. Platkajis, M. -H. Boudrias, H. Johansen-Berg, and M. Donaghy, "White matter abnormalities in methcathinone abusers with an extrapyramidal syndrome," Brain, vol. 133, no. 12, pp. 3676-3684, 2010.

[39] F. Cardoso, "HIV-related movement disorders: epidemiology, pathogenesis and management," CNS Drugs, vol. 16, no. 10, pp. 663-668, 2002.

[40] S. M. Mirsattari, C. Power, and A. Nath, "Parkinsonism with HIV infection," Movement Disorders, vol. 13, no. 4, pp. 684689, 1998. 


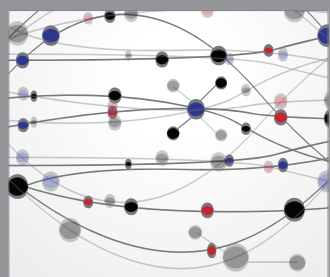

The Scientific World Journal
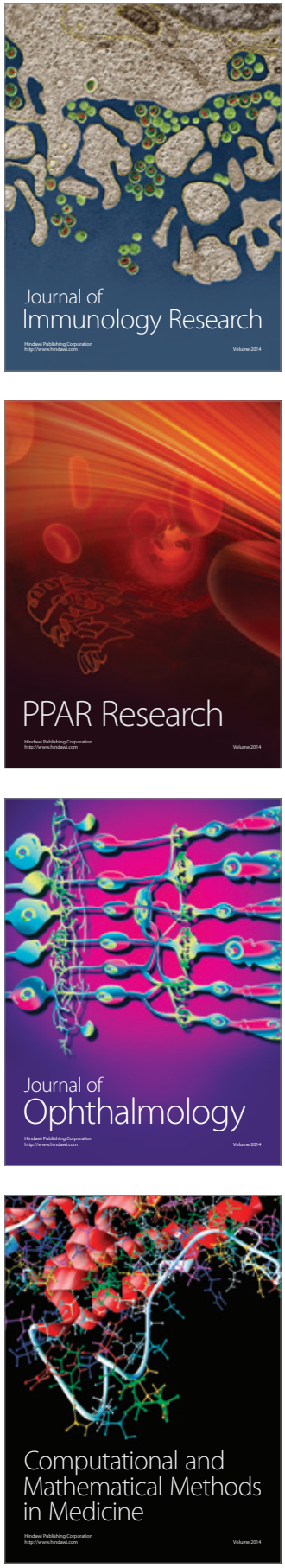

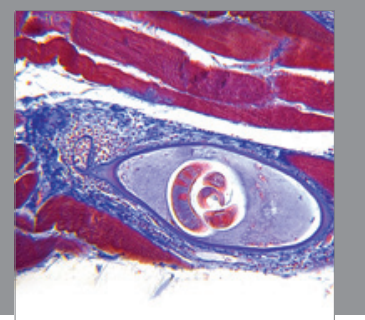

Gastroenterology

Research and Practice
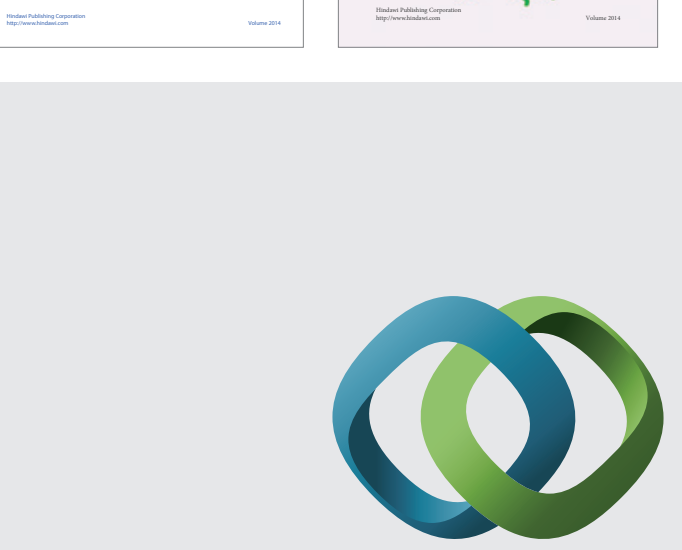

\section{Hindawi}

Submit your manuscripts at

http://www.hindawi.com
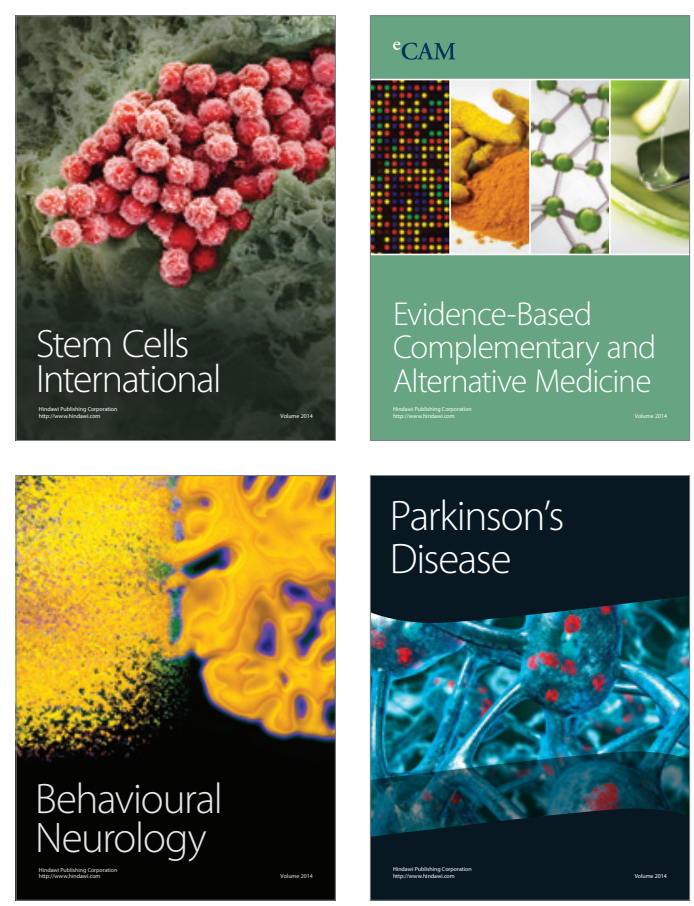

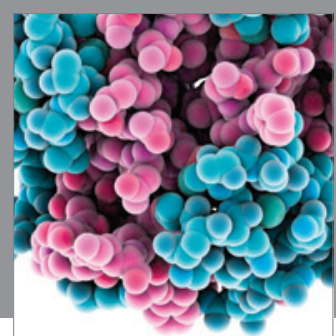

Journal of
Diabetes Research

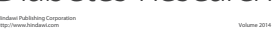

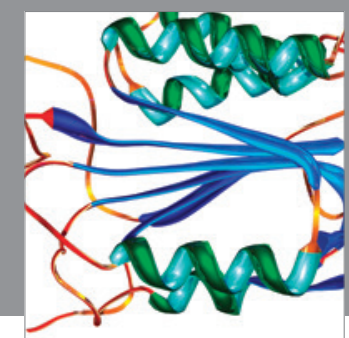

Disease Markers
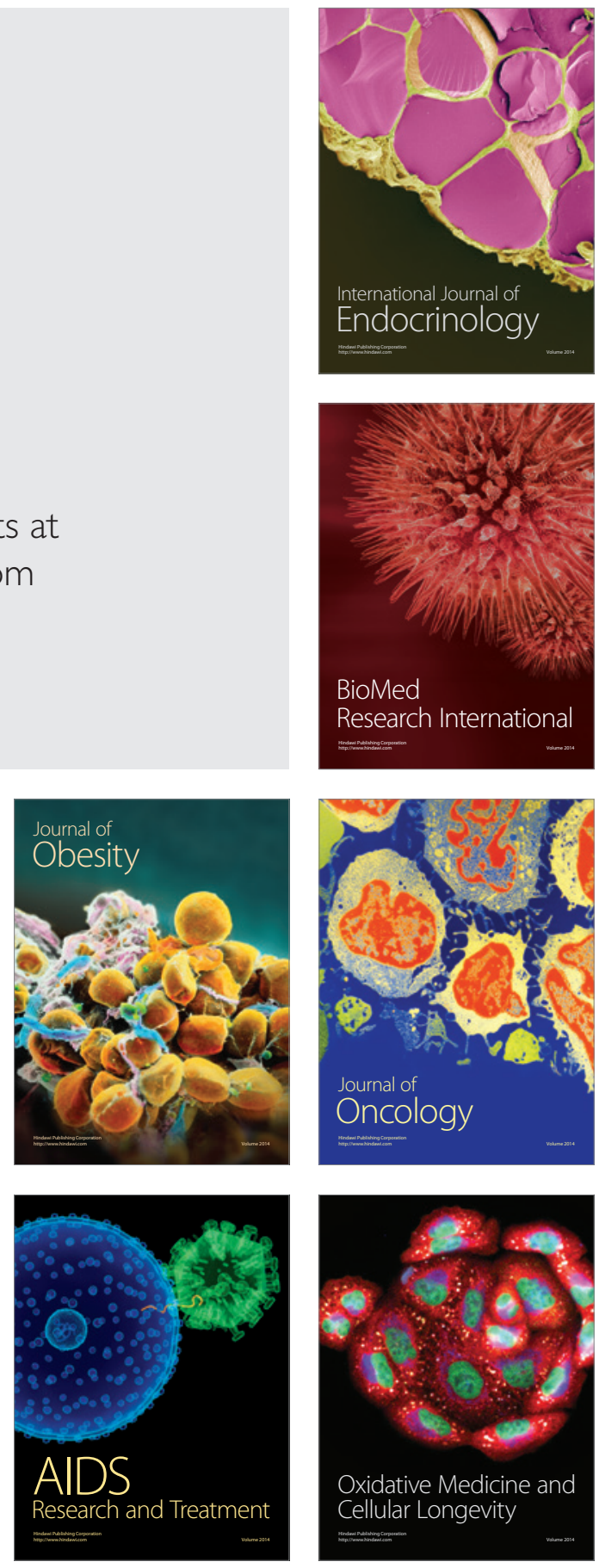